\title{
BMJ Open Digit ratio and autism spectrum disorders in the Avon Longitudinal Study of Parents and Children: a birth cohort study
}

\author{
Anna Louise Guyatt, ${ }^{1,2}$ Jon Heron, ${ }^{1}$ Bernice Le Cornu Knight, ${ }^{1}$ Jean Golding, ${ }^{3}$ \\ Dheeraj Rai ${ }^{1,4}$
}

To cite: Guyatt AL, Heron J, Knight BLC, et al. Digit ratio and autism spectrum disorders in the Avon Longitudinal Study of Parents and Children: a birth cohort study. BMJ Open 2015;5: e007433. doi:10.1136/ bmjopen-2014-007433

- Prepublication history and additional material is available. To view please visit the journal (http://dx.doi.org/ 10.1136/bmjopen-2014007433).

Received 11 December 2014 Revised 27 March 2015 Accepted 27 April 2015

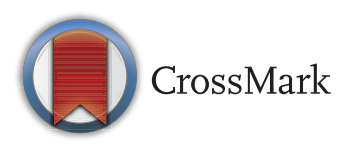

\footnotetext{
${ }^{1}$ Centre for Academic Mental Health, School of Social and Community Medicine, University of Bristol, Bristol, UK

${ }^{2} \mathrm{MRC}$ Integrative Epidemiology Unit, School of Social \& Community Medicine, University of Bristol, Bristol, UK ${ }^{3}$ Centre for Child and Adolescent Health, School of Social \& Community Medicine, University of Bristol, Bristol, UK

${ }^{4}$ Avon and Wiltshire Partnership NHS Mental Health Trust, Bristol, UK
}

Correspondence to Anna Louise Guyatt; anna.guyatt@bristol.ac.uk

\begin{abstract}
Objectives: To investigate whether second-to-fourth digit ratio (2D:4D), a measure commonly used as a proxy for fetal testosterone exposure, is associated with autism spectrum disorders (ASDs), as predicted by the extreme male brain theory of autism.
\end{abstract}

Design: A birth cohort study.

Setting: The Avon Longitudinal Study of Parents and Children (ALSPAC).

Participants: 6015 ALSPAC children with data on digit ratio, at least 1 outcome measure and information on potential confounding variables (parental

occupational class, maternal education and age at digit ratio measurement). Digit ratio was measured by the photocopy and calliper method.

Outcomes: ASD diagnosis (cases were identified previously by record linkage or maternal report) and 4 measures that combine optimally within ALSPAC to predict ASD: the Children's Communication Checklist (coherence subscale), the Social and Communication Disorders Checklist, a repetitive behaviour measure, and the Emotionality, Activity and Sociability scale (sociability subscale). These measures were dichotomised, with approximately $10 \%$ defined as the 'risk' group.

Results: Using logistic regression, we examined the association of 2D:4D with ASDs and 4 dichotomised ASD traits. Covariates were occupational class, maternal education and age at 2D:4D measurement. 2D:4D was not associated with ASDs in males (adjusted OR per $1 \mathrm{SD}$ increase in mean 2D:4D, 0.88 $(95 \% \mathrm{Cl} 0.65$ to 1.21$), \mathrm{p}=0.435)$ or females (adjusted $\mathrm{OR}=1.36(95 \% \mathrm{Cl} 0.81$ to 2.28$), \mathrm{p}=0.245)$. Similar results were observed after adjustment for IQ. There was 1 weak association between reduced coherence and increased left 2D:4D in males, in the opposite direction to that predicted by the extreme male brain theory (adjusted $\mathrm{OR}=1.15(95 \% \mathrm{Cl} 1.02$ to 1.29$)$, $p=0.023$ ). Given multiple comparisons, this is consistent with chance.

Conclusions: In this population-based study, there was no strong evidence of an association between 2D:4D and ASD diagnosis or traits, although the Cls were wide. These results are not consistent with the extreme male brain theory.

\section{Strengths and limitations of this study}

- To date, this is one of the largest populationbased studies examining the relationship between second-to-fourth digit ratio (2D:4D), which is used as a proxy for fetal testosterone exposure, and autism spectrum disorders (ASDs), separately by sex.

- This paper also examines the relationship between 2D:4D and component measures of autism, which may give insight into the less-explored relationship between digit ratio and the individual domains (social and communication, repetitive behaviours) represented in autism.

- In comparison with other small studies based in clinical settings, this study may be less prone to selection bias; the rich phenotype information within the Avon Longitudinal Study of Parents and Children (ALSPAC) allowed us to control for possible confounding variables.

- Despite its relatively large overall sample size compared with many studies, the number of autism cases in this study is still small.

- Cohort studies are prone to bias from attrition, and while the major sociodemographic predictors of attrition were controlled for in this study, it is also possible that children severely affected by ASD may have been less likely to attend clinics where 2D:4D was measured, which could bias our results.

\section{INTRODUCTION}

Autism spectrum disorders (ASDs) are pervasive developmental disorders characterised by impaired social communication and reciprocal social interaction; and restricted, repetitive patterns of behaviour, interests or activities. ${ }^{1}$ While twin studies suggest that ASDs are highly heritable, their aetiology remains largely unexplained. ${ }^{2}$ Elucidating the causes of ASD may facilitate earlier diagnosis and enhance the potential for primary 
prevention. Earlier diagnosis may lead to an improvement in educational and behavioural outcomes, a reduction in comorbid psychiatric symptoms, and a decrease in the emotional and financial stresses created by ASDs for individuals and their families. ${ }^{3}$

Various population cohorts have estimated the prevalence of ASD at approximately $1 \% .{ }^{4-7}$ These studies demonstrate a marked gender imbalance, with male-to-female ratio estimates ranging from $2: 1^{5}$ to $9: 1{ }^{8}$ depending on age of assessment, length of follow-up, and whether studies screen for ASDs or examine data on pre-existing diagnosis. Although diagnostic bias has been proposed as a partial explanation for this disparity between sexes, ${ }^{9} 10$ the consistently observed preponderance among males has generated interest into possible biological mechanisms predisposing to ASDs.

The extreme male brain (EMB) theory is the most popular hypothesis put forward to explain the sex difference in ASD. This theory postulates that children with ASD exhibit an exaggerated form of the male cognitive profile, ${ }^{11}$ and proposes that prenatal androgens are plausible biological candidates. Some evidence from animal studies suggests that testosterone may mediate cognitive differences between the sexes via organisational effects on the brain. ${ }^{12}{ }^{13}$ Recent evidence supporting the EMB theory found sex steroid levels in amniocentesis samples to be correlated with the diagnosis of ASDs. ${ }^{14}$

The index to ring finger ratio (second-to-fourth digit ratio, 2D:4D) has been widely used as a proxy for fetal testosterone exposure in autism research. ${ }^{15-25}$ An observation supporting a causal association between 2D:4D and fetal testosterone is that 2D:4D has been shown to be sexually dimorphic, ${ }^{26}$ with males generally having lower 2D:4D (ie, a relatively shorter index finger (2D) compared with their ring finger (4D)), ${ }^{27}{ }^{28}$ although this is not a unanimously reported finding. ${ }^{25}$ This sexual dimorphism is apparent from the first trimester of pregnancy, and appears to be largely static after birth, with most, ${ }^{29-33}$ but not all $^{25}$ studies finding that it is unaffected by pubertal androgen. 2D:4D has also been shown to be sexually dimorphic in endocrine models of elevated (congenital adrenal hyperplasia) and reduced fetal testosterone exposure (complete androgen insensitivity syndrome). ${ }^{28} 34-36$

Although recent reviews have concluded that lower 2D:4D is associated with ASD, ${ }^{37} 38$ many published studies are within relatively small, clinical populations which may be susceptible to selection bias and confounding. We designed a study to examine the association between 2D:4D and ASD and various autistic trait measures in a population-based cohort in the UK. The primary hypothesis being tested was that lower 2D:4D would be associated with ASDs and ASD traits.

\section{METHODS}

Study design and population

The Avon Longitudinal Study of Parents and Children (ALSPAC) is a birth cohort based in Avon, UK. In total,
14541 pregnant women with expected delivery dates between 1 April 1991 and 31 December 1992 were initially enrolled, and 13988 children were alive at 1 year. ${ }^{39}$ The study website contains details of all the data that are available through a fully searchable data dictionary: http://www.bris.ac.uk/alspac/researchers/ data-access/data-dictionary. ${ }^{40}$ The primary source of data collection was via self-completion questionnaires administered at four points during the prenatal period, then at regular intervals following birth, to both parents and the 'study child'. Since the age of 7 years, the whole cohort has been invited to a regular 'focus' clinic for a variety of hands-on assessments.

\section{Outcome variables}

\section{Autism spectrum disorders}

Within ALSPAC, the identification of children with ASD has been described elsewhere. ${ }^{41}$ Briefly, a previous record linkage study identified 86 ASD cases in ALSPAC, of which there was evidence for a strict multidisciplinary clinical assessment in 71 individuals, and in 15 others with a diagnosis of ASD recorded in school records. ${ }^{41}$ In a validation study, a consultant paediatrician reviewed the records of the individuals with ASD to confirm concordance with the International Classification of Diseases (ICD) 10 criteria. $^{41}$ In addition to cases identified by record linkage, we further identified individuals with ASD based on maternal report. At 9.5 years, mothers were asked, "Have you ever been told that your child has: autism, Asperger's syndrome or autistic spectrum disorder?" Investigators utilising maternal reports based on similar questions in other cohorts have reported an acceptable validity of identifying ASD using this approach. ${ }^{42-44}$ We cross-validated ASD cases confirmed only by maternal report by studying their association with various autistic trait measures and found strong associations (see online supplementary table S1). Of the 56 ASD cases included in this study, 24 were identified by record linkage, and 32 were identified from maternal reports of ASD diagnosis.

\section{Dichotomised ASD traits}

A previous factor analysis of 93 measures related to autism also reported four individual measures administered in ALSPAC via parental questionnaires that 'combined optimally to predict autism'. ${ }^{45}$ The coherence subscale of the Children's Communication Checklist, measured at 115 months, assesses pragmatic abnormalities in social communication. ${ }^{46}$ The Social and Communication Disorders Checklist, measured at 91 months, measured social skills (described previously). ${ }^{47}$ A Repetitive Behaviour score, measured at 69 months, asked whether the child 'repeatedly rocks the head or body, has tics or twitches or other unusual behaviour', and included a question from the Rutter scale on tics, mannerisms or twitches. ${ }^{48}$ The sociability subscale of the Emotionality, Activity and Sociability, measured at 38 months, measures tendency to affiliate 
and interact with others. ${ }^{49}$ As all the ASD scales considered were highly negatively skewed, and not readily correctable by transformation, each was dichotomised, creating a high-risk (for ASDs) group of as close to $10 \%$ of the population as possible.

\section{Explanatory variable: $2 \mathrm{D}: 4 \mathrm{D}$}

Participants were invited to a focus clinic, when 2D:4D was measured. Mean measurement age was 11.75 years. While 2D:4D was measured after the outcome measures (between approximately 2 and 8 years later, depending on the outcome), it is widely used as a measurement of the prenatal environment, and therefore we feel justified in using it as our exposure in our analysis.

2D:4D was measured by the photocopy and calliper method: the ventral surface of each palm was placed as flatly as possible onto a photocopier, ensuring that the fingers were apart and the palms pressed firmly onto the glass. The lengths of the second (index) and fourth (ring) fingers were measured using the 'Mahr digital caliper16 EX', accurate to $0.01 \mathrm{~mm}$. Each finger measured has a crease at its base: the index finger (2D) has one crease, the ring finger (4D) probably three or four. The most proximal crease was chosen and by eye, the midpoint of this was determined and the distance from this crease to the distal fingertip measured. 2D measurement was divided by 4D measurement, thus giving a 2D:4D measurement for each hand. ${ }^{40}$ To assess the legitimacy of using photocopies to calculate 2D:4D, 57 right and 48 left hands in ALSPAC have been measured previously in vivo, with high correlation between these measures and photocopies $(\mathrm{r}=0.97) .^{50}$

\section{Confounding variables}

We adjusted for the potential confounding effect of a number of sociodemographic measures. Each parent's self-reported occupation was coded as one of professional, managerial and technical, skilled non-manual, or manual, ${ }^{51}$ and the highest reported class from each child's parent(s) was recorded. Highest self-reported maternal education level was recorded as certificate of secondary education, vocational, 'O' level, 'A' level or degree. Occupational class and maternal education were used as a proxy for socioeconomic status (SES), which is known to predict loss to follow-up in ALSPAC. ${ }^{38}$ ASDs are socially patterned, ${ }^{52}$ although recent research suggests this may be in a direction opposite to that previously reported. ${ }^{53}$ We also adjusted for the age at which the participants attended the 11-year clinic (where the 2D:4D exposure was measured) to account for compliance to clinic invite, which may be related to the outcomes considered.

\section{Statistical analysis}

For the main analysis, we included children from singleton pregnancies with left and right 2D:4D measured, who had data for at least one of five outcome measures (recorded presence/absence of ASDs, or data on at least one of the four dichotomised ASD trait measures) and additionally, data on potential confounders, including parental occupational class, maternal education level and age at 2D:4D measurement $(\mathrm{n}=6015$, including 56 ASD cases, and up to 616 in a high-risk dichotomised group; see figure 1 and table 1 ).

Since the correlation between right and left hand 2D:4D was high (males 0.64 , females 0.69), we used the mean of left and right hand 2D:4D in our main analysis (see figure 2). Two outliers were removed due to their extreme 2D:4D values $(<0.75$ and $>1.25)$. Sex differences in this composite measure were assessed using a twotailed $\mathrm{t}$ test. Given the male preponderance in ASDs, and since 2D:4D is sexually dimorphic, all analyses which followed were stratified by sex, in order to assess whether the relationship of 2D:4D and ASD varied between sexes. To enable a clearer comparison of the male and female results, the 2D:4D measure was further standardised within each sex, so that a one unit change in 2D:4D represents a change by 1 SD. Raw scores (ie, non-standardised scores) are presented for descriptive tables.

A univariable logistic regression model was estimated for each ASD-related outcome in turn, using the standardised mean 2D:4D variable as a continuous exposure (see table 3). Effects were subsequently adjusted for the potential confounders listed above.

A supplementary analysis adjusted for IQ (see online supplementary table S3). As sensitivity analyses, models were repeated using left and then right hand in turn

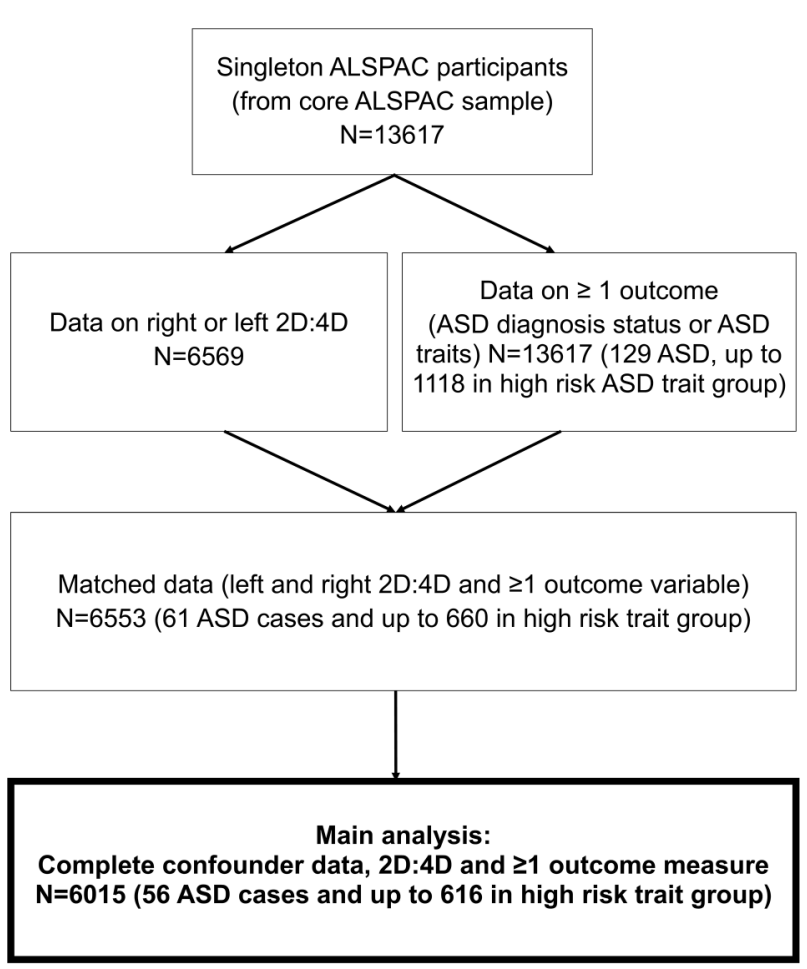

Figure 1 Description of case selection (ASD, autism spectrum disorders; ALSPAC, Avon Longitudinal Study of Parents and Children; 2D:4D, second-to-fourth digit ratio). 
Table 1 Characteristics of the study sample compared with those ALSPAC participants not included in the study*

\begin{tabular}{|c|c|c|c|}
\hline & $\begin{array}{l}\text { Study sample ( } n=6015) \\
\text { (SDs given for means) }\end{array}$ & $\begin{array}{l}\text { Other ALSPAC participants } \\
\text { ( } n \leq 7602) \text { (SDs given for } \\
\text { means) }\end{array}$ & p Value \\
\hline Male (\%) & 49 & 53 & $\leq 0.001$ \\
\hline $\begin{array}{l}\text { Autism spectrum disorder } \\
\text { (maternal and formal report) (\%) }\end{array}$ & 0.93 & 0.96 & 0.861 \\
\hline $\begin{array}{l}\text { Mean 2D:4D (those with left and right 2D:4D, } \\
\text { excluding two outliers) }\end{array}$ & $0.964(0.029)$ & $0.963(0.030)$ & 0.421 \\
\hline Age at 2D:4D measurement, months & $140.9(2.8)$ & $141.3(3.2)$ & $\leq 0.001$ \\
\hline Manual occupational background (\%) & 14.2 & 25.3 & $\leq 0.001$ \\
\hline Mother educated to degree level (\%) & 16.3 & 9.5 & $\leq 0.001$ \\
\hline
\end{tabular}

(see online supplementary tables S4A and S4B). All analyses were carried out in Stata (StataCorp), V.13.

\section{RESULTS}

The study sample and those ALSPAC participants not in this particular study were similar in terms of mean 2D:4D, age at 2D:4D measurement and ASD prevalence, but fewer participants in our study were male (see table 1). Among our study sample, there was an excess of ASD cases identified from maternal report of diagnosis only, in comparison to cases identified by record linkage, despite the equivalent prevalence of ASDs between our study sample and the remaining ALSPAC participants (see table 1). Participants in the study sample were more likely to have parents working in non-manual occupations, were more likely to have a marginally higher IQ and their mothers were more likely to be educated to
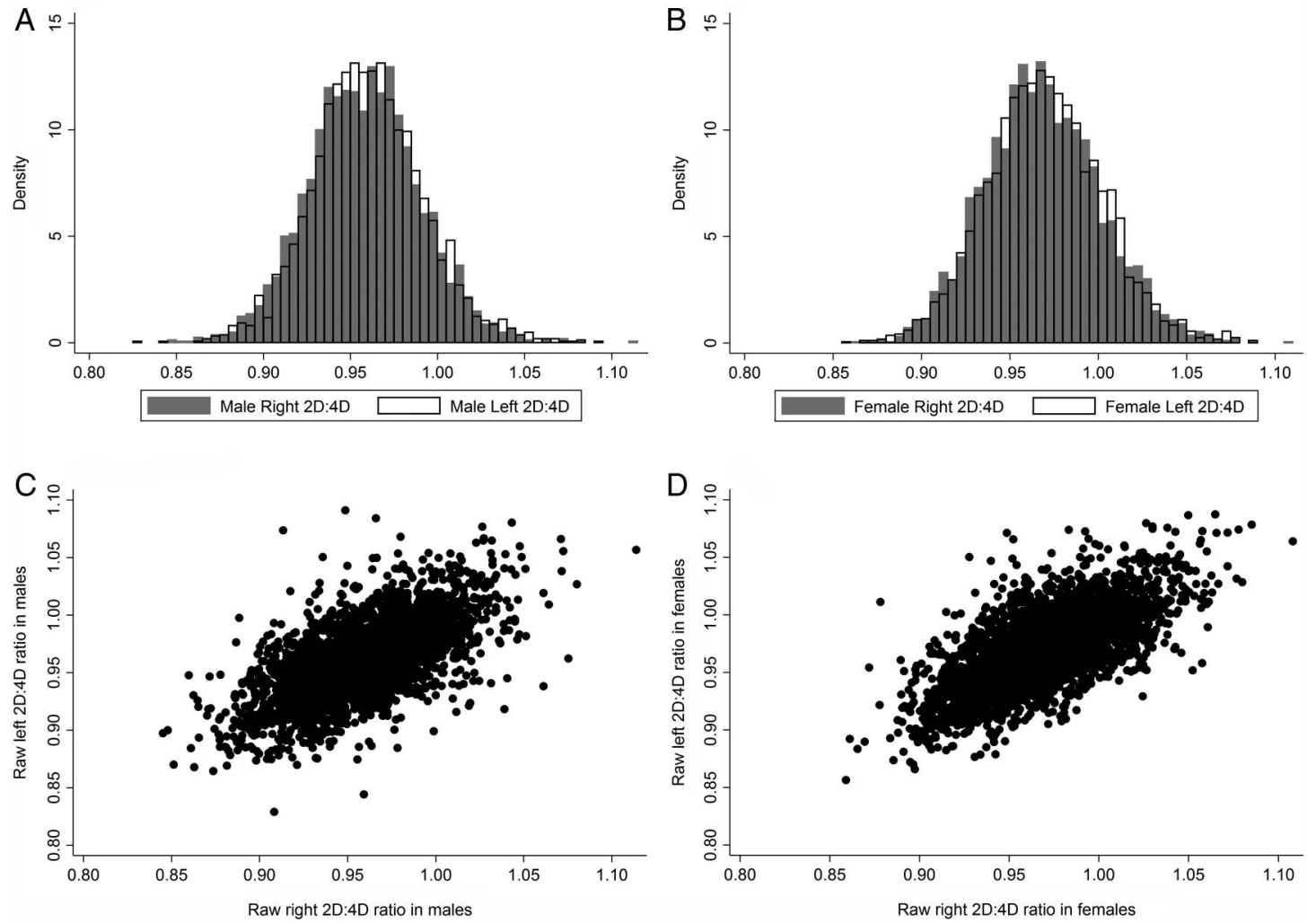

Figure 2 Histograms and scatterplots of left and right 2D:4D (second-to-fourth digit ratio), separately for males and females. (A) Histogram showing distribution of right and left 2D:4D in males. Mean (SD) of right 2D:4D: 0.958 (0.032); left 2D:4D 0.960 (0.032). (B) Histogram showing distribution of right and left 2D:4D in females. Mean (SD) of right 2D:4D 0.969 (0.033); left 0.970 (0.032). (C) Scatterplot of right and left 2D:4D in males; correlation between right and left hands: 0.64. (D) Scatterplot of right and left 2D:4D in females; correlation between right and left hands: 0.69. 
degree level, which is consistent with the social patterning of attrition previously observed within ALSPAC (see table 1) ${ }^{39}$ Within the full sample $(n=6015)$, there was strong evidence of sexual dimorphism for 2D:4D, with a mean (SE) of $0.959(0.001)$ in males and $0.969(0.001)$ in females $(\mathrm{t}=13.4, \mathrm{df}=6013$, two-tailed t test $\mathrm{p} \leq 0.001)$. This sexual dimorphism was still present in the subsample of ASD cases $(\mathrm{n}=56$, males $2 \mathrm{D}: 4 \mathrm{D}=0.955 \quad(0.003)$; females $=0.979 \quad(0.006), \mathrm{t}=3.5, \mathrm{df}=54, \mathrm{p} \leq 0.001)$. Mean 2D:4D values stratified by ASD diagnosis and the other outcomes are shown in table 2 (see online supplementary table S2 for results shown separately for right and left hand, and for results stratified by record linkage vs maternal report of ASD diagnosis).

Table 3 shows unadjusted and adjusted estimates for the increase in odds of each outcome per 1 SD increase in mean 2D:4D ratio. There was no evidence of an association between mean 2D:4D and any of the five outcomes in either sex.

We included IQ as measured by a modified version of the Wechsler Intelligence Scale for Children, as an additional covariate in a supplementary analysis. We considered this separately from our main analysis to prevent a substantial loss to our sample size, since the IQ measure was available on only 44/56 of included participants with ASDs. Another supplementary analysis examined the effect of 2D:4D by left and right hand.

Supplementary tables show (1) little impact of further adjustment for IQ (see online supplementary table S3), and (2) a broadly consistent pattern of findings when examining the effect of 2D:4D ratio for each hand in turn (see online supplementary tables S4A and S4B). One subanalysis suggested a weak association between reduced coherence (as measured by the Children's Communication Checklist) with left 2D:4D in males (adjusted OR 1.15 (95\% CI 1.02 to 1.29 ), $\mathrm{p}=0.023$, see online supplementary table S4A). There was also a trend towards increased right 2D:4D being associated with ASD diagnosis in females (adjusted OR 1.60 (95\% CI 0.97 to 2.65 ), $\mathrm{p}=0.068$, see online supplementary table
S4B). However, these results are in the opposite direction to that predicted by the prevailing theory of the EMB. One subanalysis found a trend towards masculinised 2D:4D being associated with the repetitive behaviours measure OR 0.87 (95\% CI 0.75 to 1.01 ), $\mathrm{p}=0.061$. Yet, given the number of comparisons and differing directions of association, we consider that these results are consistent with chance.

\section{DISCUSSION}

In this large UK-based birth cohort, we did not find evidence to support the hypothesis that lower 2D:4D is associated with an increased risk of ASDs. We also examined the relationship of digit ratio with dichotomised component trait measures of ASDs, including social cognition, coherence, repetitive behaviours and sociability. There were several suggestions of very weak relationships between 2D:4D and ASD traits, when the hands were studied separately. These associations were mostly directionally discordant with the extreme male theory of autism, and given the number of comparisons made, and the lack of consistent association between ASD diagnosis and 2D:4D in this study, we consider that they were due to chance.

Recent reviews have concluded that there is support for an association between masculinised 2D:4D and ASD. ${ }^{37}$ The central estimate from the most recent quantitative review was a Cohen's $\mathrm{d}$ of -0.43 , representing a moderately lower digit ratio among individuals (mostly males were studied) with autism. ${ }^{38}$ Using a t test (comparing 2D:4D between males with and without ASD - the most common comparison in the literature), we calculated that we would have had $79 \%$ power to detect this central estimate. However, we chose logistic regression methods for our primary analysis rather than a $\mathrm{t}$ test, since we were interested in adjusting for the effect of potential confounders. For consistency with previous literature, we repeated our analyses (mean 2D:4D in males with and without ASD) using a t test, and found a

Table 2 Mean (SE) of left and right second-to-fourth digit ratio, and numbers ( $n$ ) in each subgroup (autism spectrum disorder (ASD)/no ASD; high/low ASD risk), by sex

\begin{tabular}{|c|c|c|c|c|c|c|}
\hline \multirow[b]{2}{*}{ Outcome } & \multirow[b]{2}{*}{ Age } & \multirow[b]{2}{*}{ Risk group } & \multicolumn{2}{|l|}{ Males } & \multicolumn{2}{|l|}{ Females } \\
\hline & & & Mean (SE) & $\mathbf{N}$ & Mean (SE) & $\mathbf{N}$ \\
\hline \multirow[t]{2}{*}{ ASD diagnosis } & $\begin{array}{l}\text { Diagnosed } \\
\text { by } 11 \text { years }\end{array}$ & $\begin{array}{l}\text { No ASD } \\
\text { diagnosis }\end{array}$ & $0.959(0.001)$ & 2920 & $0.969(0.001)$ & 3039 \\
\hline & & ASD diagnosis & $0.955(0.003)$ & 42 & $0.979(0.006)$ & 14 \\
\hline \multirow{2}{*}{$\begin{array}{l}\text { Children's Communication Checklist } \\
\text { (Coherence subscale) }\end{array}$} & 115 months & Lower risk & $0.959(0.001)$ & 2285 & $0.970(0.001)$ & 2495 \\
\hline & & Higher risk & $0.962(0.002)$ & 302 & $0.969(0.002)$ & 167 \\
\hline Social and Communication Developmental & 91 months & Lower risk & $0.960(0.001)$ & 2260 & $0.970(0.001)$ & 2444 \\
\hline Checklist & & Higher risk & $0.959(0.002)$ & 299 & $0.970(0.002)$ & 172 \\
\hline \multirow[t]{2}{*}{ Repetitive behaviour } & 69 months & Lower risk & $0.960(0.001)$ & 2378 & $0.970(0.001)$ & 2509 \\
\hline & & Higher risk & $0.958(0.002)$ & 199 & $0.969(0.003)$ & 130 \\
\hline Emotionality, Activity and Sociability & 38 months & Lower risk & $0.959(0.001)$ & 2378 & $0.970(0.001)$ & 2540 \\
\hline Temperament Scale (Sociability subscale) & & Higher risk & $0.959(0.002)$ & 352 & $0.968(0.002)$ & 264 \\
\hline
\end{tabular}




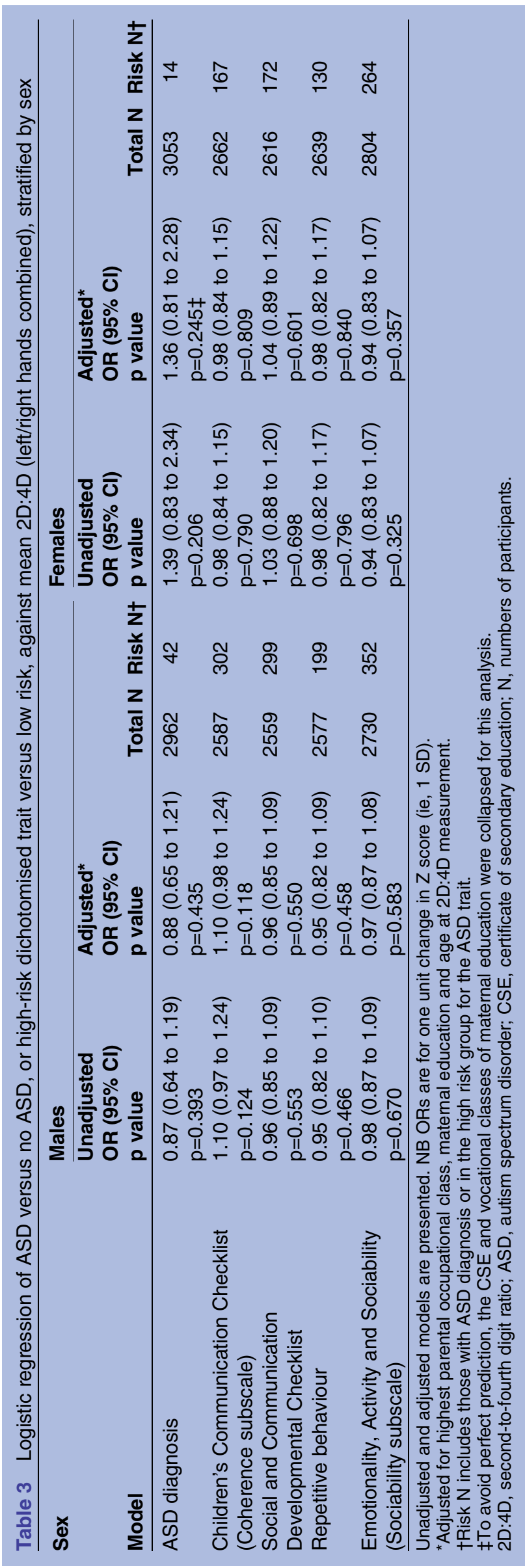

Cohen's $d$ of -0.13 ( $95 \%$ CI -0.44 to 0.17 ). It should be noted that the $\mathrm{d}$ of -0.43 , reported in the literature ${ }^{38}$ is within the CI of this estimate, albeit at the extreme lower bound.

Among the studies examining the 2D:4D-ASD diagnosis relationship (ie, not ASD trait measures), most studies recruited cases from clinical settings, ${ }^{17}$ 21-23 which may potentially limit the external validity of results, if cases recruited in a clinical setting are qualitatively different to the larger population from which they are sampled. Others recruited from mixed clinical/nonclinical populations, ${ }^{16}{ }^{25}$ schools $^{18}{ }^{20}$ and a charity. ${ }^{15}$ ASD case numbers in these studies varied from $23^{20}$ to $216 .{ }^{25}$ Of two studies with the largest number of cases to date, one was a population-based study, and these authors found an association between masculinised 2D:4D and ASD. ${ }^{15}$ Another was a clinically recruited sample, which found no relationship between 2D:4D and ASD. ${ }^{25}$ Overall, results of published studies examining the 2D:4D-ASD relationship have therefore been mixed, although the majority of them have reported an association concordant with the EMB theory. ${ }^{15} 17$ 19-22 Others have found no association, ${ }^{18} 2325$ or the inverse association to the prevailing hypothesis. ${ }^{16}$ It is also notable that many studies have examined case populations that are entirely or almost entirely male. ${ }^{17-2023}$

Although most case-control studies selected agematched and sex-matched controls, the possibility remains that the composition of the ALSPAC population may differ from these reference populations. The strengths of this study are that it is population-based, which is a design that is generally less susceptible to selection bias. We analysed the association between 2D:4D and ASD risk separately by sex, which may be important, since 2D:4D is a sexually dimorphic trait. The population studied had a comparatively high proportion of female ASD cases; however, despite this, the absolute number of female ASD cases in our study was also small $(\mathrm{n}=14)$. Although 2D:4D is sexually dimorphic, it has been found that this dimorphism may not be apparent in individuals with ASD. ${ }^{15}$ In our study, 2D:4D was sexually dimorphic in individuals with or without ASD. Further strengths of this study are that we were able to study various component measures of ASD in a large population. ${ }^{37} 54$ Although one large study has found an association between 2D:4D and ASD traits, ${ }^{54}$ reviews of previous literature have asserted that there is little overall evidence for the relationship between 2D:4D and ASD traits in healthy participants. ${ }^{37}$ Our study also found no consistent association between 2D:4D and ASD trait measures.

The ALSPAC cohort provides a rich resource of data, from which we selected variables that may have confounded an association between 2D:4D and ASD. Although our sample was population-based, the possibility of selection bias in relation to baseline recruitment or attrition in the sample over time cannot be entirely excluded. We tried to address this 
possible attrition bias by controlling for the characteristics known to be predictive of attrition in ALSPAC, such as SES. However, it is also possible that those children severely affected by ASD may have been less likely to attend clinics where 2D:4D was measuredthis could therefore result in our sample being weighted towards Asperger syndrome and other highfunctioning ASD cases. This may be relevant given that previous studies have observed a less profound difference in 2D:4D in children with Asperger syndrome compared with ASD. ${ }^{15}$ Finally, although the method used to measure 2D:4D has been shown to be reliable, ${ }^{50} 55$ and used by some of the previous studies on this topic, ${ }^{15} 17$ the possibility of error in measurement of 2D:4D cannot be excluded. Yet, it is unlikely that this would be differential for people with and without a diagnosis of ASD.

One recent study reported an association between fetal steroidogenic activity (including testosterone) and ASD, providing some direct evidence in support of the biological basis of the EMB theory of autism. ${ }^{14}$ Yet, as fetal testosterone cannot be readily measured, papers assessing the relationship between fetal testosterone and ASDs, including our study, require the existence of a proxy, for example, 2D:4D. One study cites direct evidence of 2D:4D being related to fetal testosterone-to-oestradiol ratio in humans. ${ }^{56}$ Some of the strongest indirect evidence for the fetal testosterone2D:4D relationship comes from studies associating 2D:4D with increased (congenital adrenal hyperplasia) ${ }^{28} 3436$ and decreased (complete androgen insensitivity syndrome) ${ }^{35}$ endocrine models of fetal testosterone exposure. Animal studies have provided mixed results, with some in favour of the fetal testosterone-2D:4D relationship, ${ }^{57} 58$ and others supporting the inverse association, ${ }^{59}$ or no association. ${ }^{60}$ Studies of repeats in the androgen receptor gene (correlated to testosterone) and 2D:4D have similarly provided mixed results. ${ }^{5061-63}$ A genomewide scan (including ALSPAC participants) found the minor allele of one single nucleotide polymorphism in LIN28B (linked to delayed age at menarche) ${ }^{64}$ to be associated with increased 2D:4D. ${ }^{5}$ This association was in the opposite direction to that predicted from previous work, in which lower 2D:4D was associated with delayed age at menarche, putatively via higher fetal testosterone exposure. $^{65}$ The authors therefore suggested that the relationship between fetal testosterone and 2D:4D may be more complex than first proposed, which is in agreement with previous work. $^{56}$ However, regardless as to whether 2D:4D ratio is mainly a marker of fetal testosterone, 2D:4D is clearly sexually dimorphic and related to hormonal traits within sexes, ${ }^{65}$ and thus may still be useful in the study of other sex-related traits.

To conclude, in this large population-based study, we found no consistent evidence supporting an association between lower 2D:4D ratio and increased risk of ASDs, or ASD component traits. These findings are not consistent with the EMB theory of autism.
Acknowledgements The authors are extremely grateful to the families who took part in this study, the midwives for their help in recruiting them, and the whole ALSPAC team, which includes interviewers, computer and laboratory technicians, clerical workers, research scientists, volunteers, managers, receptionists and nurses. They thank Dr Kate Northstone for her help with the data preparation. This publication is the work of the authors, who will serve as guarantors for the contents of this paper.

Contributors ALG undertook the analysis, drafted the manuscript and wrote the final version of the manuscript submitted. DR designed the study, and both $\mathrm{JH}$ and DR supervised ALG in the statistical analysis and interpretation of the results, assisted with the drafting of the manuscript, and approved the final version of the manuscript submitted. BLCK provided helpful clinical insight, assisted with the drafting of the manuscript, and approved the final version of the manuscript submitted. JG supervised ALG in interpreting the results, assisted with the redrafting of the manuscript, and approved the final version of the manuscript submitted. JH was the statistical expert for this paper.

Funding The UK Medical Research Council and the Wellcome Trust (Grant ref: 102215/2/13/2) and the University of Bristol provide core support for ALSPAC. ALG is in receipt of a Wellcome Trust PhD studentship (grant ref: 102433/Z/13/Z).

Competing interests None declared.

Ethics approval ALSPAC Ethics and Law Committee and Local Research Ethics Committee.

Provenance and peer review Not commissioned; externally peer reviewed.

Data sharing statement ALSPAC data are accessible to bona fide researchers, and the study website details conditions of use and access procedures: http:// www.bristol.ac.uk/alspac/researchers/data-access/policy/

Open Access This is an Open Access article distributed in accordance with the terms of the Creative Commons Attribution (CC BY 4.0) license, which permits others to distribute, remix, adapt and build upon this work, for commercial use, provided the original work is properly cited. See: http:// creativecommons.org/licenses/by/4.0/

\section{REFERENCES}

1. American Psychiatric Association. Diagnostic and Statistical Manual of Mental Disorders (DSM-5). Arlington, VA: American Psychiatric Publishing, 2013.

2. Folstein S, Rutter M. Infantile autism: a genetic study of 21 twin pairs. J Child Psychol Psychiatry 1977;18:297-321.

3. Koegel LK, Koegel RL, Ashbaugh K, et al. The importance of early identification and intervention for children with or at risk for autism spectrum disorders. Int J Speech Lang Pathol 2014;16: 50-6.

4. Developmental Disabilities Monitoring Network Surveillance Year 2010 Principal Investigators; Centers for Disease Control and Prevention (CDC). Prevalence of autism spectrum disorder among children aged 8 years - autism and developmental disabilities monitoring network, 11 sites, United States, 2010. MMWR Surveill Summ 2014;63:1-21.

5. Mattila ML, Kielinen M, Linna SL, et al. Autism spectrum disorders according to DSM-IV-TR and comparison with DSM-5 draft criteria: an epidemiological study. J Am Acad Child Adolesc Psychiatry 2011;50:583-92.e511.

6. Baird G, Simonoff E, Pickles A, et al. Prevalence of disorders of the autism spectrum in a population cohort of children in South Thames: the Special Needs and Autism Project (SNAP). Lancet 2006;368:210-15.

7. Idring $\mathrm{S}$, Rai $\mathrm{D}$, Dal $\mathrm{H}$, et al. Autism spectrum disorders in the Stockholm Youth Cohort: design, prevalence and validity. PLoS ONE 2012;7:e41280.

8. The NHS Information Centre for Health and Social Care. Autism spectrum disorders in adults living in households throughout England. Report from the Adult Psychiatric Morbidity Survey 2007. http://www.hscic.gov.uk/catalogue/PUB01131/aut-sp-dis-adu-liv-hoa-p-m-sur-eng-2007-rep.pdf Published 22 September 2009 (accessed 28 Aug 2014)

9. Kothari R, Skuse D, Wakefield J, et al. Gender differences in the relationship between social communication and emotion recognition. J Am Acad Child Adolesc Psychiatry 2013;52: 1148-57. 
10. Dworzynski K, Ronald A, Bolton $\mathrm{P}$, et al. How different are girls and boys above and below the diagnostic threshold for autism spectrum disorders? J Am Acad Child Adolesc Psychiatry 2012;51:788-97.

11. Baron-Cohen $\mathrm{S}$. The extreme male brain theory of autism. Trends Cogn Sci 2002;6:248-54.

12. Geschwind N, Galaburda A. Cerebral lateralization: biological mechanisms, associations and pathology: I. A hypothesis and a program for research. Arch Neurol 1985;42:428-59.

13. Rhees R, Shryne J, Gorski R. Onset of the hormone-sensitive perinatal period for sexual differentiation of the sexually dimorphic nucleus of the preoptic area. J Neurobiol 1990;21:781-6.

14. Baron-Cohen S, Auyeung B, Norgaard-Pedersen B, et al. Elevated fetal steroidogenic activity in autism. Mol Psychiatry 2015;20:369-76.

15. Manning JT, Baron-Cohen S, Wheelwright S, et al. The 2nd to 4th digit ratio and autism. Dev Med Child Neurol 2001;43:160-4.

16. Bejerot S, Eriksson JM, Bonde S, et al. The extreme male brain revisited: gender coherence in adults with autism spectrum disorder. Br J Psychiatry 2012;201:116-23.

17. De Bruin El, Verheij F, Wiegman $\mathrm{T}$, et al. Differences in finger length ratio between males with autism, pervasive developmental disorder-not otherwise specified, ADHD, and anxiety disorders Dev Med Child Neurol 2006:48:962-5.

18. Falter CM, Plaisted KC, Davis G. Visuo-spatial processing in autism -testing the predictions of extreme male brain theory. J Autism Dev Disord 2008:38:507-15.

19. Krajmer $P$, Spajdel M, Kubranska $A$, et al. $2 D: 4 D$ finger ratio in Slovak autism spectrum disorder population. Bratis/ Lek Listy 2011;112:377-9.

20. Milne $\mathrm{E}$, White $\mathrm{S}$, Campbell R, et al. Motion and form coherence detection in autistic spectrum disorder: Relationship to motor control and 2:4 digit ratio. J Autism Dev Disord 2006;36:225-37.

21. Noipayak $P$. The ratio of 2 nd and 4 th digit length in autistic children. $J$ Med Assoc Thai 2009;92:1040-5.

22. Sugie $\mathrm{Y}$, Sugie H, Fukuda T, et al. Study of HOXD genes in autism particularly regarding the ratio of second to fourth digit length. Brain Dev 2010;32:356-61

23. Aksu F, Baykara B, Ergin C, et al. [Phenotypic features in autistic individuals: the finger length ratio (2D:4D), hair whorl, and hand dominance]. Turk Psikiyatri Derg 2013;24:94-100.

24. Kothari R, Gafton J, Treasure J, et al. 2D:4D ratio in children at familial high-risk for eating disorders: the role of prenatal testosterone exposure. Am J Hum Biol 2014;26:176-82.

25. Hauth I, de Bruijn YGE, Staal W, et al. Testing the extreme male brain theory of autism spectrum disorder in a familial design. Autism Res 2014;7:491-500.

26. Ecker A. Einige Bemerkungen über einen schwankenden Charakter in der Hand des Menschen. Arch Anthropol 1875;8:67-74.

27. George R. Human finger types. Anat Rec 1930;46:199-204.

28. Honekopp J, Watson S. Meta-analysis of digit ratio 2D:4D shows greater sex difference in the right hand. Am J Hum Biol 2010;22:619-30.

29. Knickmeyer RC, Baron-Cohen S. Fetal testosterone and sex differences in typical social development and in autism. $J$ Child Neurol 2006;21:825-45.

30. Garn SM, Burdi AR, Babler WJ, et al. Early prenatal attainment of adult metacarpal-phalangeal rankings and proportions. Am J Phys Anthropol 1975;43:327-32.

31. Honekopp J, Bartholdt L, Beier L, et al. Second to fourth digit length ratio (2D:4D) and adult sex hormone levels: new data and a meta-analytic review. Psychoneuroendocrinology 2007;32:313-21.

32. McIntyre $\mathrm{MH}$, Ellison $\mathrm{PT}$, Lieberman DE, et al. The development of sex differences in digital formula from infancy in the Fels Longitudinal Study. Proc Biol Sci 2005;272:1473-9.

33. Manning JT, Scutt D, Wilson J, et al. The ratio of 2 nd to 4 th digit length a predictor of sperm numbers and concentrations of testosterone, luteinizing hormone and oestrogen. Hum Reprod 1998;13:3000-4.

34. Buck JJ, Williams RM, Hughes IA, et al. In-utero androgen exposure and 2 nd to 4th digit length ratio-comparisons between healthy controls and females with classical congenital adrenal hyperplasia. Hum Reprod 2003;18:976-9.

35. Berenbaum SA, Bryk KK, Nowak N, et al. Fingers as a marker of prenatal androgen exposure. Endocrinology 2009;150:5119-24.

36. Brown WM, Hines M, Fane BA, et al. Masculinized finger length patterns in human males and females with congenital adrenal hyperplasia. Horm Behav 2002;42:380-6.

37. Honekopp J. Digit ratio $2 \mathrm{D}: 4 \mathrm{D}$ in relation to autism spectrum disorders, empathizing, and systemizing: a quantitative review. Autism Res 2012;5:221-30.

38. Teatero ML, Netley C. A critical review of the research on the extreme male brain theory and digit ratio (2D:4D). J Autism Dev Disord 2013;43:2664-76.
39. Boyd A, Golding J, Macleod J, et al. Cohort profile: the 'children of the 90s'-the index offspring of the Avon Longitudinal Study of Parents and Children. Int J Epidemiol 2013;42:111-27.

40. Avon Longitudinal Study of Parents and Children. ALSPAC: Data Dictionary. ALSPAC. 2014. Updated 21 April, 2014. http://www.bris. ac.uk/alspac/researchers/data-access/data-dictionary/ (accessed 28 Aug 2014)

41. Williams $\mathrm{E}$, Thomas $\mathrm{K}$, Sidebotham $\mathrm{H}$, et al. Prevalence and characteristics of autistic spectrum disorders in the ALSPAC cohort. Dev Med Child Neurol 2008;50:672-7.

42. Center for Disease Control and Prevention (CDC). Mental health in the United States: parental report of diagnosed autism in children aged 4-17 years-United States, 2003-2004. MMWR Morb Mortal Wkly Rep 2006;55:481-6.

43. Lyall K, Pauls DL, Spiegelman D, et al. Fertility therapies, infertility and autism spectrum disorders in the Nurses' Health Study II. Paediatr Perinat Epidemiol 2012;26:361-72.

44. Russell G, Rodgers LR, Ukoumunne OC, et al. Prevalence of parent-reported ASD and ADHD in the UK: findings from the Millennium Cohort Study. J Autism Dev Disord 2014;44:31-40.

45. Steer CD, Golding J, Bolton PF. Traits contributing to the autistic spectrum. PLOS ONE 2010;5:e12633.

46. Bishop DV. Development of the Children's Communication Checklist (CCC): a method for assessing qualitative aspects of communicative impairment in children. J Child Psychol Psychiatry 1998;39:879-91.

47. Skuse DH, James RS, Bishop DV, et al. Evidence from Turner's syndrome of an imprinted X-linked locus affecting cognitive function. Nature 1997;387:705-8.

48. Rutter M, Tizard J, Whitmore K. Education, health \& behaviour. London, UK: Longman, 1970

49. Buss A, Plomin R. Temperament: early developing personality traits. Hillsdale, NJ: Lawrence Erlbaum, 1984.

50. Medland SE, Zayats T, Glaser B, et al. A variant in LIN28B is associated with 2D:4D finger-length ratio, a putative retrospective biomarker of prenatal testosterone exposure. Am J Hum Genet 2010;86:519-25.

51. Office of Population Censuses and Surveys. Standard Occupational Classification, Vol 3. London, UK: Her Majesty's Stationery Office, 1991.

52. Durkin MS, Maenner MJ, Meaney FJ, et al. Socioeconomic inequality in the prevalence of autism spectrum disorder: evidence from a U.S. cross-sectional study. PLoS ONE 2010;5:e11551.

53. Rai $\mathrm{D}$, Lewis $\mathrm{G}$, Lundberg $\mathrm{M}$, et al. Parental socioeconomic status and risk of offspring autism spectrum disorders in a Swedish population-based study. J Am Acad Child Adolesc Psychiatry 2012;51:467-76.e6.

54. Manning JT, Baron-Cohen S, Wheelwright S, et al. Is digit ratio (2D:4D) related to systemizing and empathizing? Evidence from direct finger measurements reported in the BBC internet survey. Pers Individ Diff 2010;48:767-71.

55. Robinson SJ, Manning JT. The ratio of 2nd to 4th digit length and male homosexuality. Evol Hum Behav 2000;21:333-45.

56. Lutchmaya S, Baron-Cohen S, Raggatt $\mathrm{P}$, et al. 2nd to 4th digit ratios, fetal testosterone and estradiol. Early Hum Dev 2004;77:23-8.

57. Talarovicova A, Krskova L, Blazekova J. Testosterone enhancement during pregnancy influences the $2 \mathrm{D}: 4 \mathrm{D}$ ratio and open field motor activity of rat siblings in adulthood. Horm Behav 2009;55:235-9.

58. Zheng Z, Cohn MJ. Developmental basis of sexually dimorphic digit ratios. Proc Natl Acad Sci USA 2011;108:16289-94.

59. Abbott AD, Colman RJ, Tiefenthaler R, et al. Early-to-mid gestation fetal testosterone increases right hand 2D:4D finger length ratio in polycystic ovary syndrome-like monkeys. PLoS ONE 2012;7:e42372.

60. Lilley T, Laaksonen T, Huitu O, et al. Maternal corticosterone but not testosterone level is associated with the ratio of second-to-fourth digit length (2D:4D) in field vole offspring (Microtus agrestis). Physiol Behav 2010;99:433-7.

61. Honekopp J. No evidence that 2D:4D is related to the number of CAG repeats in the androgen receptor gene. Front Endocrinol (Lausanne) 2013;4:185

62. Manning J, Bundred P, Newton D, et al. The second to fourth digit ratio and variation in the androgen receptor gene. Evol Hum Behav 2003:24:399-405.

63. Hurd PL, Vaillancourt KL, Dinsdale NL. Aggression, digit ratio and variation in androgen receptor and monoamine oxidase $\mathrm{A}$ genes in men. Behav Genet 2011;41:543-56.

64. He C, Kraft P, Chen C et al. Genome-wide association studies identify loci associated with age at menarche and age at natural menopause. Nat Genet 2009;41:724-8.

65. Matchock RL. Low digit ratio (2D:4D) is associated with delayed menarche. Am J Hum Biol 2008;20:487-9. 